\title{
THE REPLICATION AND DIVISION OF POLYNEMIC CHROMOSOMES
}

\author{
C. D. DARLINGTON and ASHRAFUL HAQUE \\ Botany School, Oxford
}

Received 9.vii.68

\section{The ISSUE}

THE mode of replication of chromosomes has been understood to provide us with the most decisive evidence of their molecular structure. If new material is laid down next to the old material without disturbance, the replication has been spoken of as conservative. But if, as has been shown in bacteria, the two helices of DNA have to separate before they can replicate, the process has been spoken of as semi-conservative; the separation of old and new materials will then be delayed one generation. If, again, the helices themselves are partly disintegrated before replication, we may describe the process, with its uncertain consequences as dispersive. And finally if we suppose the chromosome to be multi-stranded or polynemic (Darlington, 1955) if it is composed of multiples of double helices, presumably 2, 4, 8, 16 ...256 and so on, then the separation of the old and new materials may be delayed for several generations, how many depending on the degree of polynemy and the mode of assortment when the chromosome divides or splits.

A number of experiments have been designed and carried out to distinguish between these possibilities. Their principles have been discussed and illustrated diagrammatically by John and Lewis (1965). Their results may be summarised as follows:

(i) Taylor, Woods and Hughes (1957) used ${ }^{3} \mathrm{H}$-thymidine for making autoradiographic records of the pattern of distribution of newly synthesised DNA through two successive mitoses in Vicia faba. At the metaphase directly following the replication in presence of the tritiated thymidine $\left(X_{1}\right)$, they found that the two sister chromatids of each chromosome were identically labelled. Further, they found that in the next mitotic cycle following replication $\left(X_{2}\right)$, in the absence of the radioactive precursor but with colchicine treatment, only one of the two sister chromatids showed label. The authors concluded that chromosome reproduction takes place semiconservatively.

(ii) A little later Taylor $(1958 a, b)$ observed that sister-chromatid exchange was a common occurrence in some replicated chromosomes as evidenced by the presence of label in non-homologous segments of the sister chromatids in $X_{2}$ chromosomes. He further suggested that restitution occurred non-randomly with respect to the polarity of DNA in sisterchromatid exchanges. Taylor concluded that a chromatid is composed of a single duplex, i.e. a double strand of DNA.

(iii) La Cour and Pelc (1958) carried out a similar experiment on Vicia faba, but with one important difference. They did not use colchicine to mark the $X_{2}$ mitoses as was done by the earlier-mentioned workers. Their 
autoradiographs showed some $X_{2}$ chromosomes labelled only in one chromatid but the majority in both. They inferred that colchicine had some effect on replication. To test the validity of this view they applied colchicine and tritiated Thymidine simultaneously and noticed a segregation of label between the sister chromatids of many metaphase chromosomes of the $X_{1}$ cell generation. They concluded that their results could be explained if it was assumed that a number of DNA strands were segregating in a chromosome following the replication.

(iv) Woods and Schairer working with Vicia faba (1959), however, reported that $X_{1}$ chromosomes always showed equal label in both sister chromatids if they had replicated when colchicine and ${ }^{3} \mathrm{H}$-thymidine were present simultaneously. They further showed that the amount of the label was similar to that present in those chromosomes which had replicated in the absence of colchicine.

(v) Peacock (1963) made experiments on Vicia faba similar to those of Taylor et al. (1957) and La Cour and Pelc (1958). He found that colchicine neither influenced replication nor the frequency of sister chromatid exchange. Most chromosomes at $X_{2}$ showed the labelling pattern described by Taylor et al. but some showed iso-labelling, i.e. label in homologous regions of both sister chromatids. He concluded that chromosome replication followed a semi-conservative pattern; but the "iso-labelling" shown by some of the $X_{2}$ chromosomes could be explained only on the basis of a polynemic structure of the chromosomes (as opposed to Taylor's mononemic).

Taylor's autoradiographs (such as fig. 6 on page 520 of Taylor 1958a) show some chromosomes with iso-labelling. Taylor (1958b) himself acknowledged this but did not at first attribute any special significance to such an infrequent occurrence. Later he has referred to it as an "error" in chromosome reproduction (Taylor, 1966).

\section{Material and methods}

Most studies on this problem had been carried out on Vicia faba. For a contrast and a control, therefore, we chose to use another species. Allium sativum was seleeted for the experiments because of its large chromosomes and abundant clonal proliferation.

The cloves were grown in tap water at $24^{\circ} \mathrm{C}$. When the roots were about $1 \mathrm{~cm}$. long, they were treated with $3 \mathrm{UG} . / \mathrm{ml} .{ }^{3} \mathrm{H}$-thymidine for 10 hours. After this treatment they were washed in several changes of water and divided into two groups:

Group A were kept in water and transferred 11 hours later to 0.05 per cent. colchicine solution and fixed 3 hours later.

Group B were put in 0.02 per cent. colchicine solution for continuing further growth and were fixed 2,3 and 4 days after the treatment.

Battaglia's fixative (Ethanol 5: G.Ac.Acid 1: Chloroform 1: Formalin 1) used for 10-15 minutes gave excellent results. After fixation all roots were transferred to 95 per cent. Ethanol and stored in a refrigerator at $0^{\circ} \mathrm{G}$.

The roots were quickly run down to water immediately before hydrolysis in N.HCl for 8 minutes. They were then kept in decolourised basic Fuchsin for 1-1.5 hour after which they were squashed in a drop of 45 per cent. acetic acid. Pectinase treatment was unnecessary (Darlington and Haque, 1966). It was important to disperse the cells uniformly throughout the area 
under the cover glass leaving no clumps of the meristematic tissue. This precaution was necessary for achieving a close contact between the thoroughly flattened cells and the stripping film so as to allow the formation of a true autoradiograph of every labelled part of each chromosome in any plate (Hughes et al., 1958). The cover glass was then removed by the dry-ice method (Conger and Fairchild, 1963), leaving the cells firmly attached to the subbed (gelatinised) slides. The slides were quickly transferred to 95 per cent. Ethanol while all cells were still frozen. Before applying stripping film they were gradually run down to distilled water. After a 3-4 weeks' exposure in a refrigerator at $4^{\circ}-5^{\circ} \mathrm{C}$. the slides were processed and made permanent.

\section{Observation of LAbelling}

All meristematic cells belonging to "Group A " roots showed identical labelling in both sister chromatids of all metaphase chromosomes in cells which had incorporated the radioactive precursor. Of such cells 150 were scored. The label was present in most plates from end to end of each chromosome. Some of the plates were labelled intensely, others feebly. A few plates showed uneven labelling, but these too had the homologous segments of chromatids labelled identically. Cells with such segmental labelling suggested a dyschromous DNA synthesis as found in many plants as well as animals (Darlington and Haque, 1966).

The meristematic cells belonging to "Group B" roots fixed two days after the $\mathrm{H}^{3}$-Thymidine treatment showed labelled as well as unlabelled diploid and tetraploid metaphases (plates I-IV). In most plates the two sister chromatids in each arm of the chromosome were found widely apart owing to the colchicine-effect. Roots fixed 3 and 4 days after the treatment showed in addition labelled and unlabelled octaploid plates. The labelled tetraploid and octaploid cells represented $X_{2}$ and $X_{3}$ cell generations and each of these had inherited its label from the treatment of replicating chromosomes in the resting nucleus immediately before the $X_{1}$ mitosis.

None of our 150 labelled diploid metaphases showed any sign of the segregation of label described by La Cour and Pelc (1958). They always had both sister chromatids of each chromosome identically labelled. All the 150 labelled tetraploid (plate I) and 33 labelled octaploid plates showed the labelling pattern first described by Taylor et al. (1957) and Taylor (1958). Ghromosomes with label in one chromatid only and those with label in the non-homologous segments of the two sister chromatids (the latter brought about by exchange) were found more or less in equal numbers (48 and 52 per cent. respectively). It was rare to find a cell where the sister chromatids had not undergone exchange in any of the chromosomes. As compared with chromosomes where label was present in non-homologous segments of both sister chromatids, those where it was present in homologous segments of both (plates II, III and IV, arrows) were much less common (c. 10 per cent. of the total number of exchanges). But their presence was of great significance. For these are incompatible with the mononemic assumption.

\section{The interpretation of LABelling}

When replication has taken place in the presence of ${ }^{3} \mathrm{H}$-thymidine it thus seems that both sister chromatids are always labelled identically in 
diploid metaphases of $A$. sativum. The presence or absence of colchicine does not make any difference in the pattern of labelling. Following another replication $\left(X_{2}\right)$ in the absence of the radioactive precursor, however, several new relationships are found. The chromosomes have label either (i) in one chromatid only, or (ii) in non-homologous segments of both sister chromatids, or (iii) rarely even in the homologous segments of both the sisters. These results entirely confirm those of Peacock (1963). They can be explained, we believe, on the following three assumptions:

(i) The replication of chromosomes follows the semi-conservative pattern inherent in their double DNA structure.

(ii) Following, or in the course of, replication the sister chromatids undergo exchange. The exchanges are frequent yet one never encounters free chromatid fragments. The exchanges may have been induced by auto-radiation from within the "hot" chromosomes. Or they may be inherent in the process of splitting which gives sister chromatids.

(iii) The chromosomes are not single-stranded. They are at least dinemic and may well be polynemic (fig. 1).

\section{Polynemy and splitting}

Evidence favouring a multi-strandedness of chromosomes comes to us, apart from label-segregation, in three different ways:

(i) Exchange at a sub-chromatid level arises from irradiation of prophases in meiosis and mitosis (Swanson, 1947; Darlington, 1949; La Cour and Rutishauser, 1954).

(ii) "Reproductive errors" which were puzzling at the time were shown in the separation at anaphase of starved segments of heterochromatin in Trillium. They would now appear to be due to entanglement at points where replicated euchromatin meets non-replicated heterochromatin (Darlington and La Cour, 1940; Shaw, 1958, 1959).

(iii) Enzyme digestion studies suggest that each chromatid is a bundle of longitudinally oriented fibrils of DNA (Trosko and Wolff, 1965).

(iv) Variation in chromosome size of the order of 1 to $2^{7}$ or $2^{8}$ occurs within families and genera, and of a lower order within species, races and individuals (Darlington, 1955, 1965, table 79).

It is only in large chromosomes, those of the order of size found in Allium and Vicia, that we find it necessary to assume a polynemic structure. On this view there would be a contrast and a cleavage in structure between the mononemic chromosomes of many bacteria, protozoa, fungi, and perhaps sponges and coelenterates, and those found in the higher groups with large chromosomes. This tentative division (separating, as it does, two main fields of genetic experimentation) makes it worth while for us to re-examine a number of other genetically fundamental questions.

First is the question of the interpretation of a split occasionally and variably seen in anaphase chromosomes. Earlier arguments in favour of the significance of this split were based on the fixation of sectioned material. They could be seen to be dubious in themselves as well as mutually inconsistent (Darlington, 1935a). This is not true, however, of more recent smear preparations. Both in higher organisms (Steffenson, 1959; Kaufmann et al., 1960; Ris, 1961; Peacock, 1964) and in flagellates with the largest 
Plate I

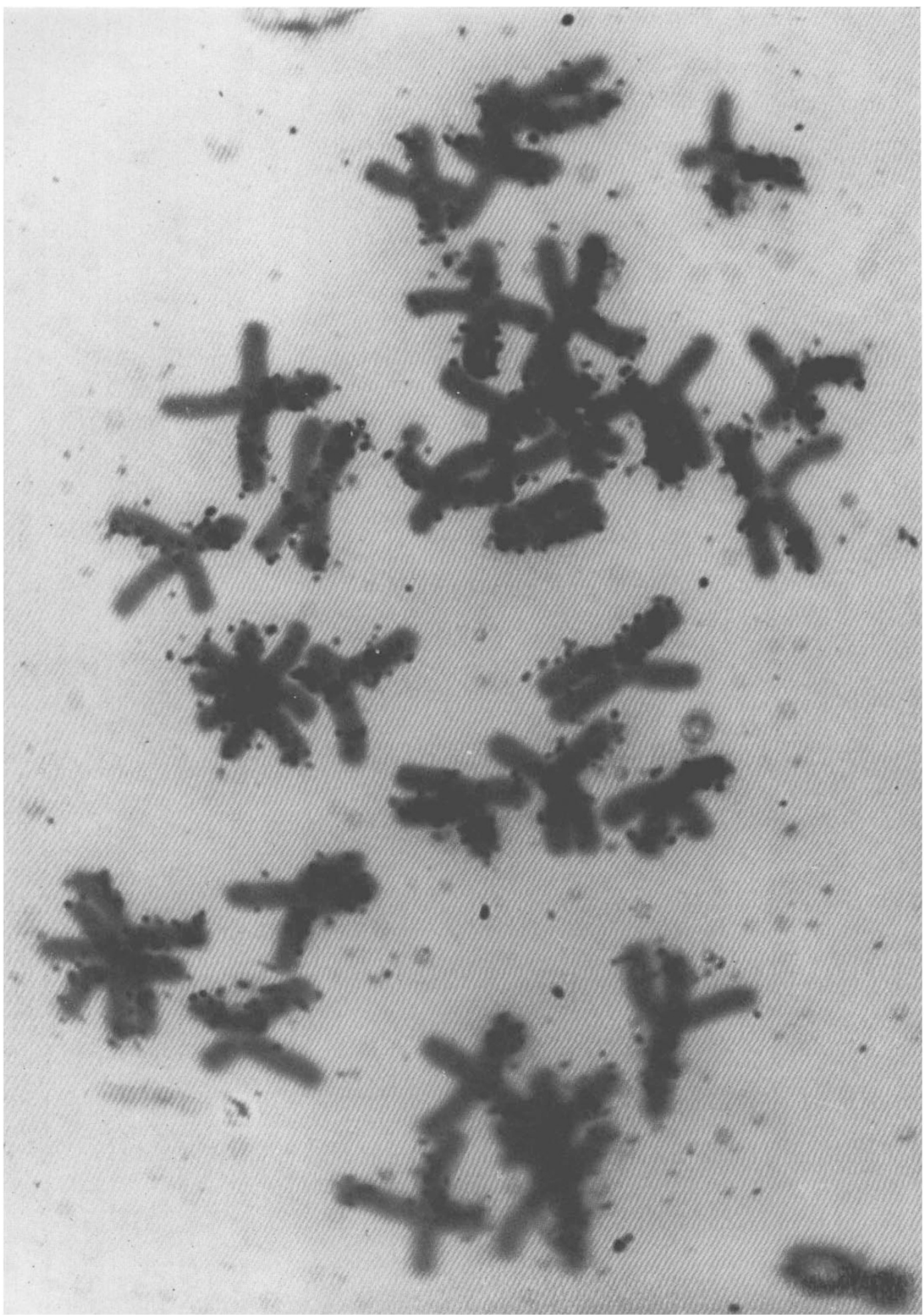

A colchicine-induced tetraploid metaphase plate of the $X_{2}$ cell cycle. Label has been given in the resting stage preceding the $X_{1}$ mitosis. Some sister chromatids show all or none labelling. Others show label in non-homologous segments of both the sisters. The total picture is thus of label-segregation. $\times c .1800$. 

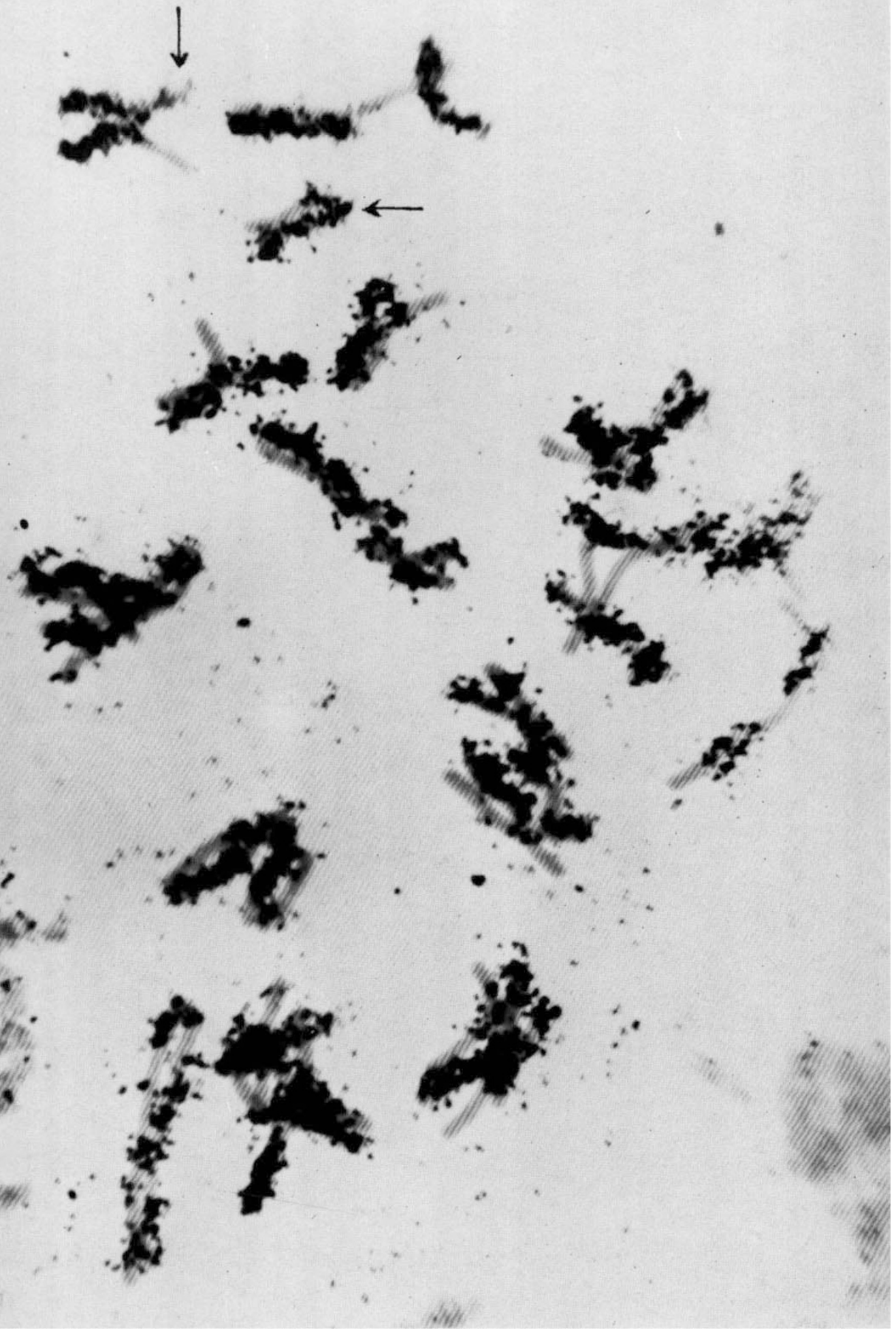

Plates II, III and IV

Tetraploid $\left(X_{2}\right)$ metaphase plates as in plate $I$ and showing label segregation for most chromosomes. But some chromosomes show iso-labelling, i.e. homologous arms or parts of arms of sister chromatids are labelled. These chromosomcs are indicated by arrows. $\times c .1600$. 
Plate III

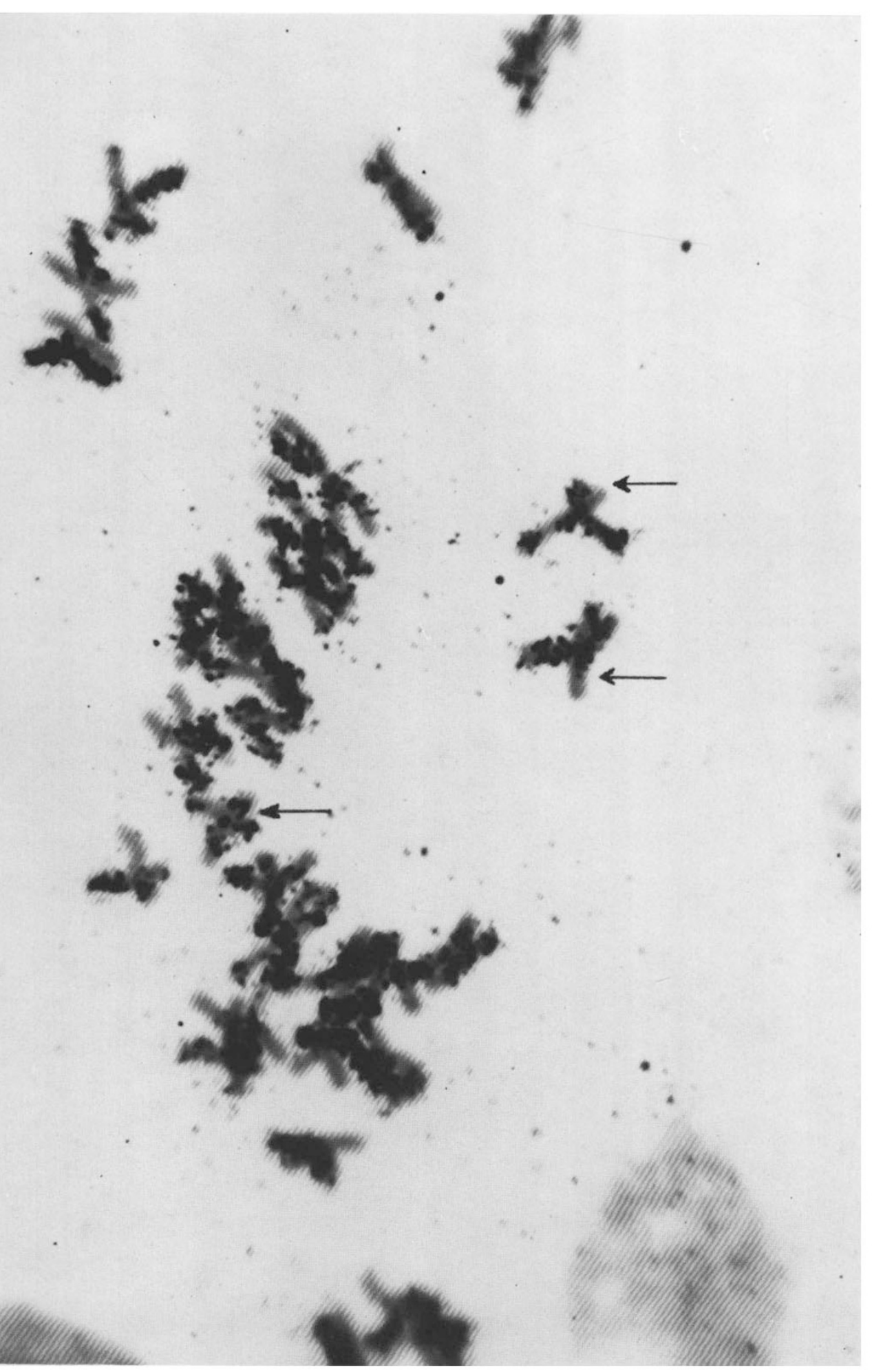


Plate IV

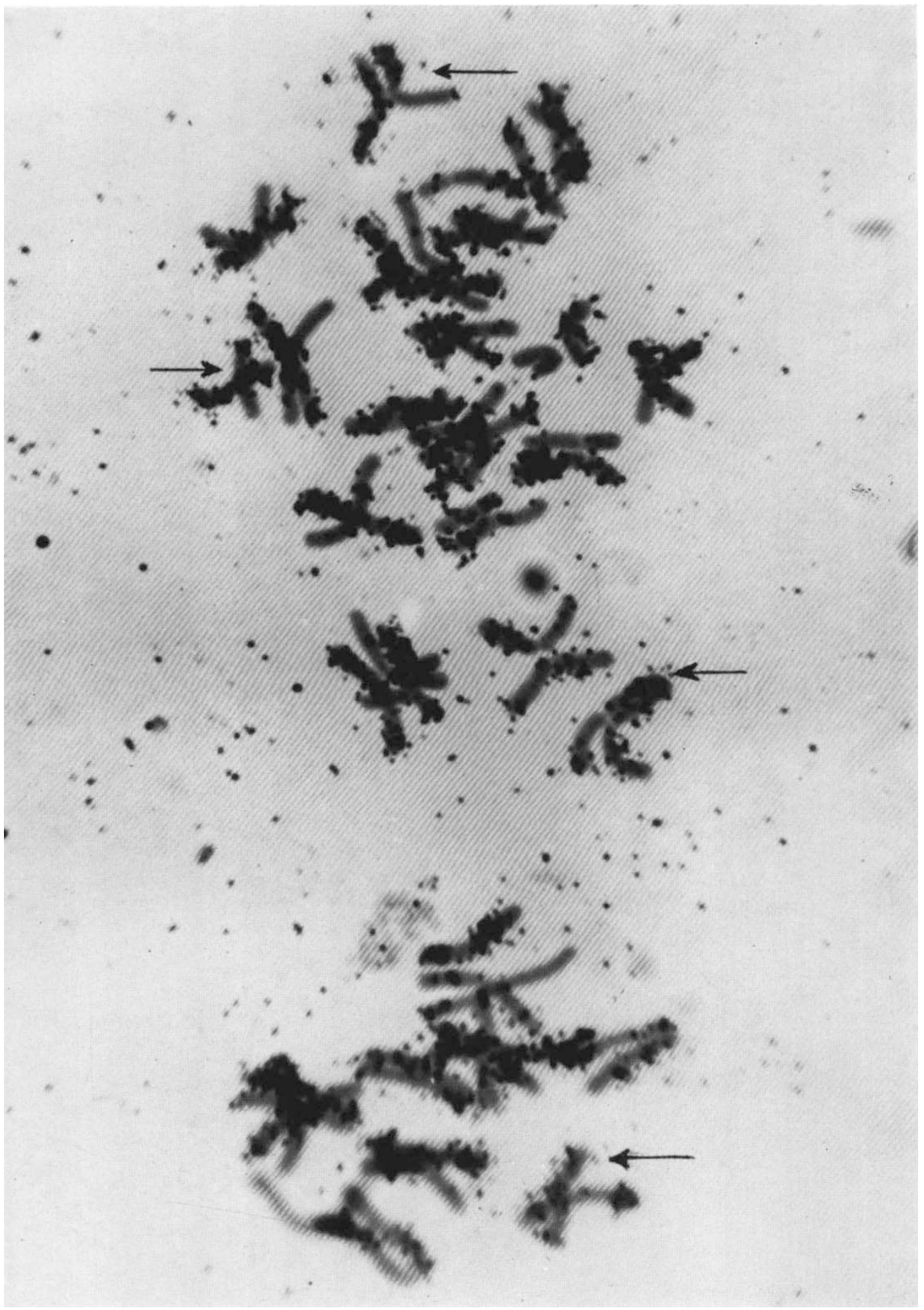


of all chromosomes (Cleveland, 1949) splits have been seen in such preparations of the chromosomes at anaphase. These are evidence of genuine doubleness. As such they are important. They do not, however, correspond with anything seen in living chromosomes or revealed by cine-photography.

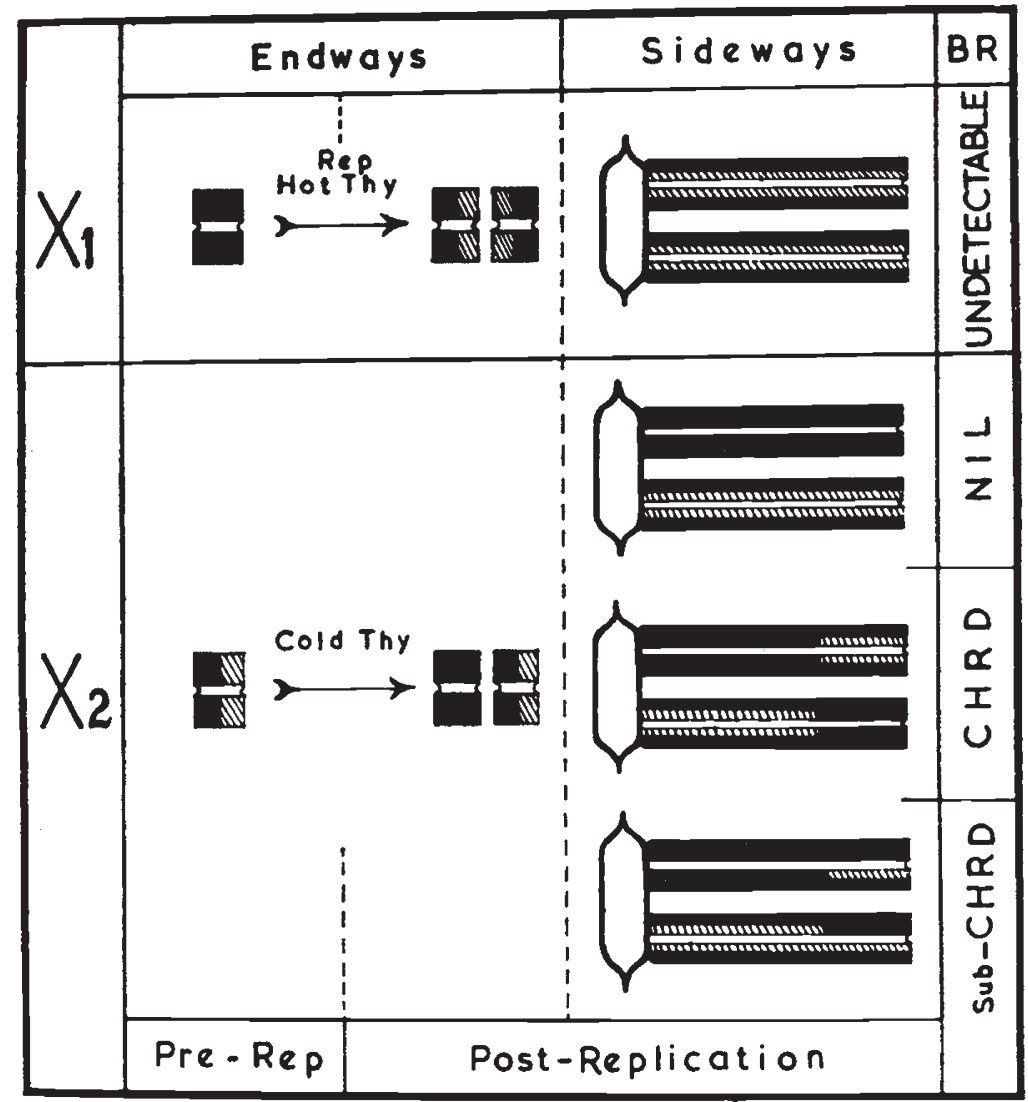

FIG. 1.-Diagram explaining the labelling pattern in $X_{1}$, and $X_{2}$ mitotic cycles after ${ }^{3} \mathrm{H}$ thymidine incorporation in the resting stage immediately preceding $X_{1}$ mitosis. A chromatid has been shown as dinemic for convenience in representation. It can as well be assumed to be polynemic. Rep = replication, Hot Thy and Cold Thy, $\mathrm{H}^{3}$ - and $\mathrm{H}^{2}$-Thymidine, $\mathrm{CHRD}=$ Chromatid, $\mathrm{BR}=$ Breakage-reunion (exchange), Solid black $=$ " Cold " component, Hatched $=$ " Hot" component.

What has happened? It seems that the jointly coiled multiple chromosomes have been prematurely pressed apart to give paired threads. The result is an artefact. And although it is not regularly reproducible we may describe it as a characteristic artefact. It demonstrates two-strandedness. The making visible of the separation of the two strands is not, to be sure, a natural one. The natural split in the multiple thread follows the synthesis and replication which usually take place in the resting nucleus. It is this split which occurs and is invariably seen in the succeeding prophase, at the beginning of prophase in mitosis, at diplotene in meiosis. And it is this split, we suppose, which determines the separation of the chromosomes at anaphase, the breakage and reunion of crossing over, and the exposure of 
the position of this crossing over as a chiasma at diplotene (Darlington, $1935 b)$.

These principles relate crossing over with chiasma formation and have been applied successfully to mapping the centromere in fungi as well as in higher organisms (Catcheside, 1951). They therefore seem to override the differences between mononemic and polynemic chromosomes.

The second important question is that of the connection, the variably timed but normally indispensible connection, between the processes of reproduction of chromosomes, in the resting stage at mitosis and their splitting which is preceded by the prophase at meiosis. Several recent pieces of evidence suggest a dissociation, made possible by polynemy between synthesis and separation. In precociously polymitotic pollen in maize, chromosomes may enter mitosis without either splitting or reproduction (Darlington, 1965, p. 699). And in mutant pollen in Tradescantia chromosomes may reproduce without splitting (G. and K. Oestergren, 1966). Similarly, chromosomes always split close to the end of pachytene in a normal meiosis. But reproduction, in its timing and even in its occurrence, may be separated from the split in ways characteristic of different organisms (Darlington, 1965, p. 680: Scutigera also p. 719). And, of course, there are very many instances of the timing of prophase, its precocity in relation to this split, being modified by particular genotypes which lead to asynapsis (Darlington and Haque, 1955).

Thus it seems that, while reproduction and splitting are exactly coordinated in most mitoses and meioses, co-ordination can break down. The breakdown may be the abnormal result of experimental treatment or genetic mutation. But it may also be an adaptive part of the chromosome mechanism of species associated with the suppression of meiosis and with parthenogenesis. Such breakdowns must be responsible for cyclical variations in chromosome size.

The third question at issue is that of the adaptive value and evolutionary origin of polynemy. Its advantage would probably be in allowing the chromosomes to control much larger cells and by its reversibility, as distinct from polyploidy, to allow for sudden changes of size during differentiation. Its undoubted value would lie in the ability of the polynemic chromosome to convey torsion over greater distances and so make possible a lower frequency of evenly distributed cross-overs and chiasmata which we know to be adaptively advantageous (Darlington, 1958).

\section{Summary}

Experiments on the root-meristems of Allium sativum whose chromosomes were labelled with $\mathrm{H}^{3}$-Thymidine have shown that:

1. Both sister chromatids of each chromosome are seen to be identically labelled in the $X_{1}$ cell cycle immediately following replication in presence of the labelling agent.

2. After a second as well as a third, $X_{2}$ and $X_{3}$, cell cycle with replication in the absence of the labelling agent, most chromosomes show a clean segregation of labelled and unlabelled chromatids or chromatid segments. Rarely, however, label appears in homologous segments of both sister chromatids. They show iso-labelling. 
3. This evidence is consistent with a semi-conservative pattern of replication provided that the chromosomes are polynemic rather than mononemic.

4. After replication the sister chromatids sometimes undergo exchanges which may be inherent in the separation of newly organised sister chromatids.

5. Colchicine, which was used to identify $X_{2}$ and $X_{3}$ mitoses, seems to have no effect on these properties of replication.

6 . The assumption of polynemy allows us to understand the diverse relations between the internally significant process of replication and the externally significant process of division or splitting in mitosis; and also consequences of these processes in pairing, crossing over and chiasma formation at meiosis.

Acknowledgment.-We are indebted to the Science Research Council (U.K.) for their support. One of us (A. H.) is also grateful to the authorities of the East Pakistan Agricultural University, Mymensingh, for granting leave which enabled him to visit Oxford.

\section{REFERENGES}

CATCheside, D. G. 1951. The Genetics of Micro-Organisms. Pitman, London.

CLEVELAND, L. R. 1949. The whole life cycle of chromosomes and their coiling systems. Trans. Amer. Philos. Soc., 39, 1-100.

CONGER, A. D., AND FAIRCHILD, L. M. 1963. A quick-freeze method for making smear slides permanent. Sten. Technolog $y, 28,281-283$.

DARLington, c. D. 1935a. The old terminology and the new analysis of chromosome behaviour. Ann. Bot., 49, 579-586.

Darlington, C. D. 1935b. The time, place and action of crossing-over. 7. Genet., 31, $185-212$.

Darlington, c. D. 1949. The working units of heredity. Hereditas, Suppl. Vol., 189-200. DARlington, C. D. 1955. The chromosome as a physico-chemical entity. Nature, 176, 1139-1144.

Darlington, C. D. 1958. Evolution of Genetic Systems. Oliver and Boyd, Edinburgh.

Darlington, C. D. 1965. Cytology. Churchill, London.

Darlington, c. D., AND haQue, A. 1955. The timing of mitosis and meiosis in Allium ascalonicum: a problem of differentiation. Heredity, $9,117$.

DARLINGton, c. D., AND haQUE, A. 1966. Organisation of DNA synthesis in Rye chromosomes. Chromosomes Today, 1, 102-107.

DARLINGTON, C. D., AND LA COUR, L. F. 1940. Nucleic acid starvation of chromosomes in Trillium. F. Genet., 40, 185-213.

HUGHes, W. L., BOND, v. P., BREGKer, G., CRONKITE, E. P., PAINTER, R. B., QUASTleR, H., AND SHERMAN, F. G. 1958. Cellular proliferation in the mouse as revealed by autoradiography with tritiated thymidine. Proc. Nat. Acad. Sci. U.S.A., 44, 476-483.

JohN, B., AND LEWIS, K. R. 1955. The meiotic system. Protoplasmatologia, 6, 42-52.

KAUFMAN, B. P., GAY, H., AND MCDONALD, M. 1960. Organisational patterns within chromosomes. Int. Rev. Cytol., 9, 77-127.

LA COUR, L. F., AND PELG, s. R. 1958. Effect of colchicine on the utilisation of labelled thymidine during chromosomal reproduction. Nature, 182, 506-508.

LA COUR, L. F., AND RUTISHAUSER, A. 1954. X-ray breakage experiments with endosperm. 1. Subchromatid breakage. Chromosome, 6, 696-709.

OESTERGREN, G., AND K. 1966. Mitosis with undivided chromosomes. III Inhibition of chromosome reprSouction in Tradescantia by specific mutations. Chromosomes Today, 1 , $128,130$.

PEACOCK, w. J. 1963. Chromosome duplication and structure as determined by autoradiography. Proc. Nat. Acad. Sci., U.S.A., 49, 793-801.

PEACOCK, w. J. 1964. Chromosome replication. Symp. "Genes and Chrs.", Buenos Aires, 101-131.

RIS, H. 1961. Ultrastructure and molecular organisation of genetic systems. Canad. V. Genet. Cytol., 3, 95-120. 
SHAW, G. w. 1958. Adhesion loci in the differentiated heterochromatin of Trillium species. Chromosoma, 9, 292-304.

sHAW, G. w. 1959. The nature of differential reactivity in the heterochromatin of Trillium and Paris spp. Cytologia, 24, 50-61.

Steffenson, D. 1959. A comparative view of the chromosome. Brookhaven Symp. Biol., 12, 103-124.

swanson, c. P. 1947. X-ray and Ultraviolet studies on pollen tube chromosomes. II. The quadripartite structure of prophase chromosomes in Tradescantia. Proc. Nat. Acad. Sci., U.S.A., 33, 229-232.

TAYLOR, H. J., WOODS, P. S., AND HUGHES, W. L. 1957. The organisation and duplication of chromosomes as revealed by autoradiographic studies using tritium labelled thymidine. Proc. Nat. Acad. Sci., U.S.A., 43, 122-128.

TAYLOR, H. J. 1958a. Sister chromatid exchanges in Tritium-labelled chromosomes. Genetics, 43, 515-529.

TAYLOR, H. J. 1958b. The organisation and duplication of genetic material. Proc. 10th Int. Nat. Cong. Genet., 1, 63-78.

TAYLOR, H. J. 1963. The replication and organisation of DNA in chromosomes. Molecular Genetics. Academic Press, New York.

TAYloR, H. J. 1966. The duplication of chromosomes. 3. Wiss. Konf. Ges. Deutscher Naturf. Semmering bei Wien 1965. Springer, Berlin, New York.

TROSKO, J. E., AND WOLFF, s. 1965. Strandedness of Vicia faba chromosomes as revealed by enzyme digestion studies. F. Cell. Biol., 26, 125-135.

wOoDs, P. S., AND SCHAIRER, M. v. 1959. Distribution of newly synthesised Deoxyribonucleic Acid in dividing chromosomes. Nature, 183, 303-305. 